\title{
Passive leg raising can predict fluid responsiveness in patients placed on venovenous extracorporeal membrane oxygenation
}

Pierre-Grégoire Guinot ${ }^{1 *}$, Elie Zogheib ${ }^{1}$, Mathieu Detave ${ }^{1}$, Mona Moubarak', Vincent Hubert ${ }^{1}$, Louise Badoux', Eugénie Bernard ${ }^{1}$, Patricia Besserve ${ }^{1}$, Thierry Caus $^{2,3}$ and Hervé Dupont ${ }^{1,3}$

\begin{abstract}
Introduction: In ICUs, fluid administration is frequently used to treat hypovolaemia. Because volume expansion (VE) can worsen acute respiratory distress syndrome (ARDS) and volume overload must be avoided, predictive indicators of fluid responsiveness are needed. The purpose of this study was to determine whether passive leg raising (PLR) can be used to predict fluid responsiveness in patients with ARDS treated with venovenous extracorporeal membrane oxygenation (ECMO).
\end{abstract}

Methods: We carried out a prospective study in a university hospital surgical ICU. All patients with ARDS treated with venovenous ECMO and exhibiting clinical and laboratory signs of hypovolaemia were enrolled. We measured PLR-induced changes in stroke volume ( $\triangle P L R S V)$ and cardiac output ( $\triangle P L R C O)$ using transthoracic echocardiography. We also assessed PLR-induced changes in ECMO pump flow ( $\triangle P L R P O)$ and PLR-induced changes in ECMO pulse pressure ( $\triangle P L R P P)$ as predictors of fluid responsiveness. Responders were defined by an increase in stroke volume (SV) > 15\% after VE.

Results: Twenty-five measurements were obtained from seventeen patients. In $52 \%$ of the measurements $(n=13)$, SV increased by $>15 \%$ after VE (responders). The patients' clinical characteristics appeared to be similar between responders and nonresponders. In the responder group, PLR significantly increased SV, cardiac output and pump flow $(P<0.001)$. $\triangle$ PLRSV values were correlated with VE-induced SV variations $\left(r^{2}=0.72, P=0.0001\right)$. A $10 \%$ increased $\triangle P L R S V$ predicted fluid responsiveness with an area under the receiver operating characteristic curve (AUC) of $0.88 \pm 0.07$ (95\% confidence interval $\left(\mathrm{Cl}_{95}\right)$ : 0.69 to $\left.0.97 ; P<0.0001\right), 62 \%$ sensitivity and $92 \%$ specificity. On the basis of AUCS of $0.62 \pm 0.11\left(C_{95}: 0.4\right.$ to $\left.0.8 ; P=0.31\right)$ and $0.53 \pm 0.12\left(C_{95}: 0.32\right.$ to $\left.0.73, P=0.79\right)$, respectively, $\triangle P L R P P$ and $\triangle P L R P O$ did not predict fluid responsiveness.

Conclusions: In patients treated with venovenous ECMO, a $>10 \% \triangle P L R S V$ may predict fluid responsiveness. $\triangle P L R P P$ and $\triangle P L R P O$ cannot predict fluid responsiveness.

Keywords: acute respiratory distress syndrome, fluid responsiveness, passive leg raising, extracorporeal membrane oxygenation, venovenous

\section{Introduction}

In ICUs, fluid administration is frequently used to treat hypovolaemia to enhance cardiac function by increasing preload. Many studies have demonstrated that fluid responsiveness can be predicted by using respiratory

\footnotetext{
* Correspondence: guinotpierregregoire@gmail.com

'Department of Anesthesiology and Critical Care, Amiens University Hospital, Place Victor Pauchet, Amiens, F-80054, France Full list of author information is available at the end of the article
}

derivative indices (pulse pressure variation $(\Delta$ respPP), stroke volume $(\mathrm{SV})$ variation $(\Delta \mathrm{respSV})$ and aortic velocity-time integral variation ( $\Delta$ respVTIAo)) [1-5]. From a clinical perspective, owing to altered alveolar capillary membrane permeability, fluid management is critical to the outcomes of ARDS patients [6,7]. In ARDS, dynamic indices predictive of fluid responsiveness present limitations related to the effects of the cardiopulmonary disease on heart-lung interactions (right-sided heart failure,
C Biomed Central 
pulmonary hypertension and protective ventilation) [8-12]. In addition, as fluid overload can be harmful, indices using passive leg raising (PLR) have been validated [13-17]. By shifting blood from the lower limbs and splanchnic compartment, PLR is a safe, reversible manoeuvre that mimics fluid expansion [16]. In adult patients with refractory ARDS, despite ventilatory optimisation by means of routine therapies (protective mechanical ventilation, prone position and nitric oxide) $[18,19]$, the use of respiratory assistance such as venovenous extracorporeal membrane oxygenation (ECMO) ensures oxygenation and decarboxylation [20-22]. Venovenous ECMO consists of a circuit supplied by a centrifugal pump without a venous reservoir. Venous return and pump venous injection are preload- and postloaddependent processes that run in parallel to the human right-sided circulation and may interfere with it [23-25]. In hypovolaemic patients, PLR prediction of fluid responsiveness is unclear. Blood transfer induced by PLR may be modified by the preload dependence of the ECMO. Because patients supported by ECMO are the frailest ARDS patients, because they present with several interrelated diseases that limit the use of respiratory dynamic criteria, and because fluid therapy can affect outcomes, it is necessary to validate additional manoeuvres such as PLR that may better discriminate responders from nonresponders.

The main goal of this study was to answer the following question: Can PLR be used to predict fluid responsiveness in ARDS patients placed on venovenous ECMO? As ECMO pump flow (PO) is a preload-dependent process, we assumed that changes in $\mathrm{PO}$ between baseline and PLR ( $\triangle \mathrm{PLRPO}$ ) could reflect a preloaddependent condition. Thus, we analysed the predictive value of $\triangle \mathrm{PLRPO}$.

\section{Materials and methods \\ Patients}

We conducted a prospective, observational study at the Amiens Sud University Hospital surgical ICU over a period of 13 months (from November 2009 to December 2010). ARDS patients treated with venovenous ECMO for whom the intensivist recommended volume expansion (VE) were enrolled in the study. Patients with poor cardiac echogenicity were not included. All patients had been sedated and paralysed with continuous infusion of midazolam, sufentanil and cisatracurium. All patients underwent invasive arterial pressure monitoring, central venous catheterisation and echocardiography several times daily because of their various diseases.

This study was approved by the Institutional Review Board (IRB) for human subjects at our hospital. Informed consent was waived because the IRB considered the protocol to be part of routine clinical practice.

\section{Extracorporeal membrane oxygenation}

The ECMO circuit consists of an inflow venous line inserted into the right femoral vein and advanced through the inferior vena cava close to the right atrium, an outflow venous line inserted into the right internal jugular vein as far as the right atrium, a ROTAFLOW centrifugal pump (MAQUET GmbH \& Co. AG, Rastatt, Germany) and a QUADROX PLS oxygenator (MAQUET GmbH \& Co. AG). Inflow and outflow cannula sizes are reported in Table 1.

\section{Measurements}

The following clinical features were measured: age; gender; weight; surgical, medical and/or clinical problems; and the main diagnosis. Transthoracic echocardiography (TTE) was performed by a single physician using a Philips EnVisor Ultrasound System (Philips Medical Systems, Suresnes, France). The diameter of the aortic annulus $(\mathrm{AoD})$ was measured using a long-axis parasternal view at patient inclusion. Aortic area $(\mathrm{Aa})$ was calculated by using the equation $\mathrm{Aa}\left(\right.$ in $\left.\mathrm{cm}^{2}\right)=\left(\pi \times \mathrm{AoD}^{2}\right) / 4$. The aortic velocity-time integral (VTIAo) ratio was measured using pulsed Doppler ultrasonography with a fivechamber apical view. SV was calculated by using the equation SV $($ in $\mathrm{mL})=$ VTIAo $\times$ Aa. Cardiac output (CO) was calculated using the formula $\mathrm{CO}$ (in $\mathrm{mL} / \mathrm{min}$ ute) $=\mathrm{SV} \times$ heart rate (HR). Mean echocardiographic values were calculated from five measurements (regardless of the respiratory cycle) and analysed a posteriori. The reproducibility of aortic area and VTIAo measurements were tested before the study. Intraindividual and interindividual reproducibility were calculated from the mean value of three of ten patients. The mean ( \pm standard deviation) intraindividual and interindividual reproducibility values were $4.4 \pm 3.9 \%$ and $4.4 \pm 3.2 \%$, respectively. The ECMO PO was measured on the monitor screen by a physician at the different steps of the study. Maximum and minimum pump flow $\left(\mathrm{PO}_{\max }\right.$ and $\mathrm{PO}_{\mathrm{min}}$, respectively) were recorded for one minute. Mean $\mathrm{PO}$ was calculated as $\mathrm{PO}$ (in $\mathrm{mL} /$ minute) $=$ $\left(\mathrm{PO}_{\max }+\mathrm{PO}_{\min }\right) / 2$. $\mathrm{PO}$ variation was called the pulse index $(\mathrm{PI})$ and calculated as $\mathrm{PI}=\left(\mathrm{PO}_{\max }-\mathrm{PO}_{\min }\right) /$ $\left(\mathrm{PO}_{\max }+\mathrm{PO}_{\min } / 2\right) \times 100$. The $\mathrm{PO} /$ rotation per minute (RPM) ratio (expressed in $\mathrm{mL} /$ rotation/minute) was calculated as $(\mathrm{PO} / \mathrm{RPM}) \times 1,000$. Central venous pressure (CVP) and blood pressure were measured with a transducer zeroed at the level of the midaxillary line. $\Delta$ respPP was measured on frozen waveforms on the monitor by calculating $\Delta$ respPP $=\left(\mathrm{PP}_{\max }-\mathrm{PP}_{\min }\right) /$ $\left.\left[\left(\mathrm{PP}_{\max }+\mathrm{PP}_{\min }\right) / 2\right)\right] \times 100$.

\section{Study protocol}

Systolic arterial pressure (SAP), median arterial pressure (MAP), diastolic arterial pressure (DAP), $\triangle$ respPP, 
Table 1 Main patient characteristics at the time of inclusion ${ }^{a}$

\begin{tabular}{|c|c|c|c|c|c|c|c|c|c|c|}
\hline Patient & Gender & $\begin{array}{l}\text { ARDS } \\
\text { aetiology }\end{array}$ & $\begin{array}{l}\text { Outflow/ } \\
\text { inflow } \\
\text { cannula } \\
\text { size } \\
\text { (French) }\end{array}$ & $\begin{array}{c}\mathrm{PaO}_{2} / \mathrm{FiO}_{2} \\
\text { ratio at } \\
\mathrm{ECMO} \\
\text { assistance }\end{array}$ & $\begin{array}{c}\text { Time from } \\
\text { assistance } \\
\text { with ECMO } \\
\text { (days) }\end{array}$ & $\begin{array}{l}\text { Tidal } \\
\text { volume } \\
\text { (mL/kg) }\end{array}$ & $\begin{array}{c}\text { Respiratory } \\
\text { compliance } \\
(\mathrm{mL} / \\
\left.\mathrm{cmH}_{2} \mathrm{O}\right)\end{array}$ & Norepinephrine & $\begin{array}{l}\text { Epinephrine } \\
\text { or } \\
\text { dobutamine }\end{array}$ & $\begin{array}{l}\text { Acute cor } \\
\text { pulmonale }\end{array}$ \\
\hline \multirow[t]{2}{*}{1} & M & $\begin{array}{l}\text { Community- } \\
\text { acquired } \\
\text { pneumonia }\end{array}$ & $18 / 25$ & 42 & 2 & 4 & 17.6 & Yes & No & Yes \\
\hline & & & & & 8 & 6 & 34.3 & Yes & No & Yes \\
\hline 2 & $F$ & H1N1 & $18 / 22$ & 45 & 3 & 2.6 & 9.6 & No & Yes & Yes \\
\hline 3 & M & $\mathrm{H} 1 \mathrm{~N} 1$ & $18 / 23$ & 42 & 5 & 4.1 & 16 & Yes & No & Yes \\
\hline \multirow[t]{2}{*}{4} & M & $\begin{array}{l}\text { Postoperative } \\
\text { bacterial } \\
\text { pneumonia }\end{array}$ & $18 / 25$ & 37 & 2 & 5.4 & 26.9 & Yes & Yes & Yes \\
\hline & & & & & 12 & 7.1 & 41.8 & Yes & Yes & Yes \\
\hline \multirow[t]{2}{*}{5} & M & Peritonitis & $18 / 25$ & 60 & 4 & 4.4 & 24.6 & Yes & No & No \\
\hline & & & & & 7 & 5.1 & 28.7 & Yes & No & No \\
\hline 6 & $\mathrm{~F}$ & H1N1 & $18 / 24$ & 45 & 5 & 3.7 & 14.7 & yes & Yes & Yes \\
\hline \multirow[t]{2}{*}{7} & M & $\begin{array}{l}\text { Postoperative } \\
\text { bacterial } \\
\text { pneumonia }\end{array}$ & $18 / 25$ & 38 & 6 & 6 & 23.5 & Yes & Yes & Yes \\
\hline & & & & & 6 & 3.8 & 10.4 & Yes & Yes & Yes \\
\hline 8 & $\mathrm{~F}$ & $\begin{array}{l}\text { Community- } \\
\text { acquired } \\
\text { pneumonia }\end{array}$ & $18 / 25$ & 50 & 7 & 5.8 & 21.3 & No & No & No \\
\hline \multirow[t]{2}{*}{9} & F & $\mathrm{H} 1 \mathrm{~N} 1$ & $16 / 24$ & 39 & 4 & 3.6 & 15 & Yes & Yes & Yes \\
\hline & & & & & 12 & 5 & 27.3 & Yes & No & No \\
\hline \multirow[t]{2}{*}{10} & M & Chest trauma & $18 / 25$ & 38 & 5 & 3.4 & 20.8 & Yes & No & Yes \\
\hline & & & & & 11 & 4.8 & 23.8 & No & No & No \\
\hline \multirow[t]{2}{*}{11} & $\mathrm{~F}$ & $\begin{array}{l}\text { Community- } \\
\text { acquired } \\
\text { pneumonia }\end{array}$ & $16 / 25$ & 58 & 11 & 5.6 & 16.3 & No & No & No \\
\hline & & & & & 15 & 8 & 24.4 & No & No & Yes \\
\hline \multirow[t]{2}{*}{12} & M & $\begin{array}{l}\text { Postoperative } \\
\text { bacterial } \\
\text { pneumonia }\end{array}$ & $16 / 25$ & 45 & 4 & 2.9 & 12.2 & Yes & Yes & Yes \\
\hline & & & & & 8 & 4.6 & 15.9 & Yes & No & Yes \\
\hline 13 & M & $\begin{array}{l}\text { Community- } \\
\text { acquired } \\
\text { pneumonia }\end{array}$ & $18 / 25$ & 87 & 5 & 2.8 & 11.7 & No & Yes & Yes \\
\hline 14 & M & $\begin{array}{l}\text { Bronchopleural } \\
\text { fistula }\end{array}$ & $18 / 25$ & 52 & 10 & 2.9 & 12.2 & Yes & Yes & Yes \\
\hline 15 & M & $\begin{array}{l}\text { Postoperative } \\
\text { bacterial } \\
\text { pneumonia }\end{array}$ & $18 / 25$ & 44 & 5 & 3.3 & 16.7 & No & Yes & Yes \\
\hline 16 & M & H1N1 & $18 / 24$ & 50 & 6 & 5.7 & 38.2 & Yes & No & No \\
\hline 17 & $\mathrm{~F}$ & $\begin{array}{l}\text { Community- } \\
\text { acquired } \\
\text { pneumonia }\end{array}$ & $16 / 23$ & 46 & 3 & 3.4 & 16.7 & Yes & No & Yes \\
\hline
\end{tabular}

${ }^{a} \mathrm{ARDS}$, acute respiratory distress syndrome; $\mathrm{PaO}_{2} / \mathrm{FiO}_{2}$ ratio, ratio of partial pressure of arterial oxygen to fraction of inspired oxygen; ECMO, extracorporeal membrane oxygenation; $M$, male; $F$, female. Patients $1,4,5,7,9,10,11$ and 12 underwent two sets of measurements.

CVP, CO, VTIAo and HR were recorded at baseline with the patient in a semirecumbent position $\left(45^{\circ}\right.$ angle). Automatic bed raising from this position raised the patient's lower limbs to a $45^{\circ}$ angle while the patient's trunk was lowered from a semirecumbent to supine position [11]. A second set of SAP, MAP, DAP,
HR, CVP, PO, $\triangle$ respPP and VTIAo measurements was recorded when VTIAo plateaued at its highest value. The patient was then returned to the initial semirecumbent position, and VE was initiated with $500 \mathrm{~mL}$ of saline for 15 minutes. A third set of measurements was recorded after VE. The ventilator settings, drugs 
and ECMO RPM were maintained at constant levels throughout the study period.

\section{Statistical analysis}

SV measured before and after VE was used to distinguish responders from nonresponders with changes in SV of $>15 \%$ and $<15 \%$, respectively $[7,9,12]$. The results are expressed as medians (25th to 75th interquartile ranges). Changes in haemodynamic variables were compared between responders and nonresponders before PLR and VE using the nonparametric MannWhitney $U$ test. For the overall population and for each subgroup (responders and nonresponders), the nonparametric Wilcoxon rank-sum test was used to assess the statistical significance of changes in PLR-induced haemodynamic parameters or VE and to compare the prePLR values of the variables measured at baseline (HR, SAP, DAP, MAP, SV, VTIAo, PO and PI). Spearman's rank correlation coefficient was used to test linear correlations. A receiver operating characteristic curve (ROC) and its corresponding positive and negative likelihood ratios were generated for PLR-induced changes in SV ( $\triangle$ PLRSV), CO ( $\triangle \mathrm{PLRCO})$ and PO ( $\triangle \mathrm{PLRPO})[26]$. Area under the ROC (AUC) values for $\triangle$ PLRSV and $\triangle$ PLRCO were compared. Differences with a $P$ value $<$ 0.05 were considered statistically significant. Statistical analysis was performed using IBM SPSS Statistics 18 software (IBM Corp., Armonk, NY, USA) and MedCalc 8.1.0.0 software (Mariakerke, Belgium).

\section{Results}

Twenty-five measurements were obtained from seventeen patients. PLR manoeuvres and VE were performed twice on eight patients on different days and under different respiratory and haemodynamic conditions. The patients had acute circulatory failure associated with septic shock and primary or secondary ARDS. The most common cause of heart failure was acute cor pulmonale, defined on the basis of echocardiographic criteria [27]. The patient characteristics are reported in Table 1. All VEs were performed on the basis of the following criteria: arterial hypotension (SAP $<90 \mathrm{mmHg}$ and/or MAP $<70 \mathrm{mmHg})(n=12)$, oligoanuria (urine output < $0.5 \mathrm{~mL} / \mathrm{kg} /$ hour or $<20 \mathrm{~mL} /$ hour $)(n=9)$, skin mottling and/or leg coldness $(n=4)$.

Of the 25 patients who underwent VE, 13 (52\%) were responders: SV increased by $>15 \%$. At baseline, the haemodynamic and echocardiographic parameters were similar in both groups. None of these parameters were predictive of fluid responsiveness. Tables 2 and 3 present the haemodynamic, echocardiographic and PO parameters. SV and CO increases during PLR and after VE were correlated (respectively, $r^{2}=0.72, P=0.0001$
Table 2 Comparison of haemodynamic parameters between responders and nonresponders ${ }^{\mathrm{a}}$

\begin{tabular}{|c|c|c|c|}
\hline Parameters & $\begin{array}{l}\text { Responders } \\
(n=13)\end{array}$ & $\begin{array}{c}\text { Nonresponders } \\
(n=12)\end{array}$ & $\begin{array}{c}P \\
\text { values }\end{array}$ \\
\hline \multicolumn{4}{|l|}{$\overline{\mathrm{HR}}(\mathrm{bpm})$} \\
\hline Baseline & 95 (82 to 106) & 95 (81 to 104$)$ & 0.95 \\
\hline PLR & 95 (76 to 104) & 91 (77 to 106) & 0.95 \\
\hline $\begin{array}{l}\text { Volume } \\
\text { expansion }\end{array}$ & 93 (78 to 105) & 96 (79 to 106$)$ & 0.72 \\
\hline \multicolumn{4}{|l|}{$\mathrm{SAP}(\mathrm{mmHg})$} \\
\hline Baseline & 108 (99 to 121$)$ & 105 (92 to 115$)$ & 0.47 \\
\hline PLR & 117 (93 to 121$)$ & 107 (86 to 120$)$ & 0.46 \\
\hline $\begin{array}{l}\text { Volume } \\
\text { expansion }\end{array}$ & $120(111 \text { to } 130)^{\mathrm{b}}$ & 107 (99 to 126) & 0.2 \\
\hline \multicolumn{4}{|l|}{$\mathrm{DAP}(\mathrm{mmHg})$} \\
\hline Baseline & 59 (49 to 71$)$ & 57 (46 to 70$)$ & 0.62 \\
\hline PLR & 61 (44 to 67 ) & 61 (44 to 70 ) & 1 \\
\hline $\begin{array}{l}\text { Volume } \\
\text { expansion }\end{array}$ & $67(49 \text { to } 72)^{b, c}$ & 56 (50 to 70$)$ & 0.51 \\
\hline \multicolumn{4}{|l|}{ MAP (mmHg) } \\
\hline Baseline & 77 (65 to 84$)$ & 75 (62 to 83 ) & 0.62 \\
\hline PLR & 77 (61 to 84$)$ & 72 (58 to 84$)$ & 0.64 \\
\hline $\begin{array}{l}\text { Volume } \\
\text { expansion }\end{array}$ & $83(71 \text { to } 90)^{b, c}$ & 71 (67 to 87) & 0.27 \\
\hline \multicolumn{4}{|l|}{ CVP (mmHg) } \\
\hline Baseline & 7 (5 to 13$)$ & 11 (8 to 15$)$ & 0.08 \\
\hline PLR & $12(8 \text { to } 14)^{b}$ & $12(10$ to 13$)$ & 0.68 \\
\hline $\begin{array}{l}\text { Volume } \\
\text { expansion }\end{array}$ & $12(10 \text { to } 15)^{b}$ & $13(10 \text { to } 17)^{b}$ & 0.46 \\
\hline \multicolumn{4}{|l|}{$\Delta r e s p P P(\%)$} \\
\hline Baseline & $6(4$ to 8$)$ & 7 (4 to 10$)$ & 0.59 \\
\hline PLR & $6(4$ to 7$)$ & $9(5$ to 11$)$ & 0.14 \\
\hline $\begin{array}{l}\text { Volume } \\
\text { expansion }\end{array}$ & 5 (4 to 8 ) & 7 (5 to 10$)$ & 0.11 \\
\hline \multicolumn{4}{|l|}{ VTI (cm/second) } \\
\hline Baseline & 20 (15.2 to 25$)$ & $\begin{array}{c}16.1(13.7 \text { to } \\
21.6)\end{array}$ & 0.3 \\
\hline PLR & 24.7 (17.7 to 28.3$)$ & $\begin{array}{l}15.8(12.9 \text { to } \\
22.3)\end{array}$ & 0.03 \\
\hline $\begin{array}{l}\text { Volume } \\
\text { expansion }\end{array}$ & $25.4 \underset{c}{(19.1}$ to 30$)^{b}$ & 16 (14 to 21.4$)$ & $<0.001$ \\
\hline \multicolumn{4}{|l|}{$\mathrm{SV}(\mathrm{mL})$} \\
\hline Baseline & 72 (50 to 88$)$ & 55 (49 to 84$)$ & 0.7 \\
\hline PLR & $86(59 \text { to } 99)^{b}$ & 58 (48 to 85$)$ & 0.1 \\
\hline $\begin{array}{l}\text { Volume } \\
\text { expansion }\end{array}$ & $89(66 \text { to } 109)^{b, c}$ & 60 (48 to 82 ) & 0.02 \\
\hline \multicolumn{4}{|l|}{ CO (L/minute) } \\
\hline Baseline & 5.8 (4 to 8.3 ) & 5.6 (4.3 to 7.8$)$ & 0.96 \\
\hline PLR & $5.9(4.7 \text { to } 9.6)^{b}$ & 5.8 (4 to 6.6 ) & 0.27 \\
\hline $\begin{array}{l}\text { Volume } \\
\text { expansion }\end{array}$ & $7.5(5.2 \text { to } 10.1)^{\mathrm{b}, \mathrm{c}}$ & $5.2(4.4$ to 7.7$)$ & 0.03 \\
\hline
\end{tabular}

a PLR, passive leg raising; $H R$, heart rate; SAP, systolic arterial pressure; DAP, diastolic arterial pressure; MAP, median arterial pressure; CVP, central venous pressure; $\triangle$ respPP, respiratory pulse pressure variation; VTI, velocity time integral of aortic blood flow; SV, stroke volume; $\mathrm{CO}$, cardiac output. ${ }^{\mathrm{b}} \mathrm{P}<0.05$ vs baseline; ${ }^{c} P<0.05$ vs PLR. Values are medians (25th to 75 th interquartile ranges). 
Table 3 Comparison of extracorporeal membrane oxygenation parameters between responders and nonresponders ${ }^{\mathrm{a}}$

\begin{tabular}{|c|c|c|c|}
\hline Parameters & Responders $(n=13)$ & Nonresponders $(n=12)$ & $P$ values \\
\hline \multicolumn{4}{|l|}{$\overline{\mathrm{PO}}$ (L/minute) } \\
\hline Baseline & 4.70 (3.45 to 4.99$)$ & 4.25 (3.49 to 5.02$)$ & 0.91 \\
\hline PLR & 4.76 (3.24 to 5.05$)$ & $4.23(3.5$ to 5$)$ & 0.83 \\
\hline Volume expansion & $4.81(3.36 \text { to } 5.14)^{b, c}$ & 4.20 (3.57 to 5.09$)$ & 0.97 \\
\hline \multicolumn{4}{|l|}{ PI (\%) } \\
\hline Baseline & 0.95 (0.59 to 1.9$)$ & 0.78 (0.48 to 1.20$)$ & 0.35 \\
\hline PLR & $0.68(0.4 \text { to } 1)^{b}$ & 0.69 (0.45 to 1$)$ & 0.78 \\
\hline Volume expansion & $0.62(0.6 \text { to } 1.3)^{b, c}$ & $0.91(0.54$ to 1.1$)$ & 0.05 \\
\hline RPM & 3950 (3078 to 4004$)$ & 3838 (3010 to 3966) & 0.96 \\
\hline \multicolumn{4}{|c|}{ PO/RPM ratio (mL/RPM) } \\
\hline Baseline & $1.24(1.07$ to 1.31$)$ & 1.23 (1.11 to 1.32$)$ & 0.83 \\
\hline PLR & $1.26(1.03 \text { to } 1.33)^{b}$ & 1.23 (1.13 to 1.32$)$ & 0.62 \\
\hline Volume expansion & $1.27(1.06 \text { to } 1.32)^{b, c}$ & $1.25(1.13$ to 1.32$)$ & 0.68 \\
\hline \multicolumn{4}{|l|}{$\mathrm{PO} / \mathrm{CO}$ ratio (\%) } \\
\hline Baseline & 66 (60 to 91) & 75 (56 to 93) & 0.7 \\
\hline PLR & $60(51 \text { to } 77)^{\mathrm{b}}$ & 73 (62 to 105$)$ & 0.05 \\
\hline Volume expansion & $54(49 \text { to } 69)^{\mathrm{b}, c}$ & $72(55$ to 100$)$ & 0.05 \\
\hline
\end{tabular}

${ }^{a} \mathrm{PLR}$, passive leg raising; $\mathrm{PO}$, pump outflow; $\mathrm{Pl}$, pulse index; $\mathrm{RPM}$, rotations per minute; $\mathrm{CO}$, cardiac output. ${ }^{\mathrm{b}} P<0.05$ vs baseline; ${ }^{\mathrm{C}} P<0.05$ vs $\mathrm{PLR}$. Values are medians (25th to 75 th interquartile ranges).

(Figure 1); $\left.r^{2}=0.70, P=0.0001\right)$. This correlation was not observed for PO $\left(r^{2}=0.07, P=0.79\right)$.

In the whole population, the AUCs were $0.88 \pm 0.07$ for $\triangle$ PLRSV (95\% confidence interval $\left(\mathrm{CI}_{95}\right): 0.69$ to $0.97 ; P<0.0001)$ and $0.87 \pm 0.07$ for $\triangle \mathrm{PLRCO}\left(\mathrm{CI}_{95}\right.$ : 0.67 to $0.97 ; P<0.0001$ ) (Figure 2). The $\triangle \mathrm{PLRCO}$ and $\triangle$ PLRSV AUCs were not different $(P=0.66)$. $\triangle$ PLRPO had poor sensitivity and specificity, as well as a poor AUC: $0.53 \pm 0.12\left(\mathrm{CI}_{95}: 0.32\right.$ to $\left.0.73 ; P=0.79\right)$ (Figure $2)$. The $\triangle$ respPP AUC was $0.56 \pm 0.12\left(\mathrm{CI}_{95}: 0.35\right.$ to $0.77 ; P=0.59$ ) (Figure 2). The $\triangle$ PLRPP AUC was $0.62 \pm$ $0.11\left(\mathrm{Cl}_{95}: 0.4\right.$ to $0.8 ; P=0.31$ ) (Figure 2$)$. In ten

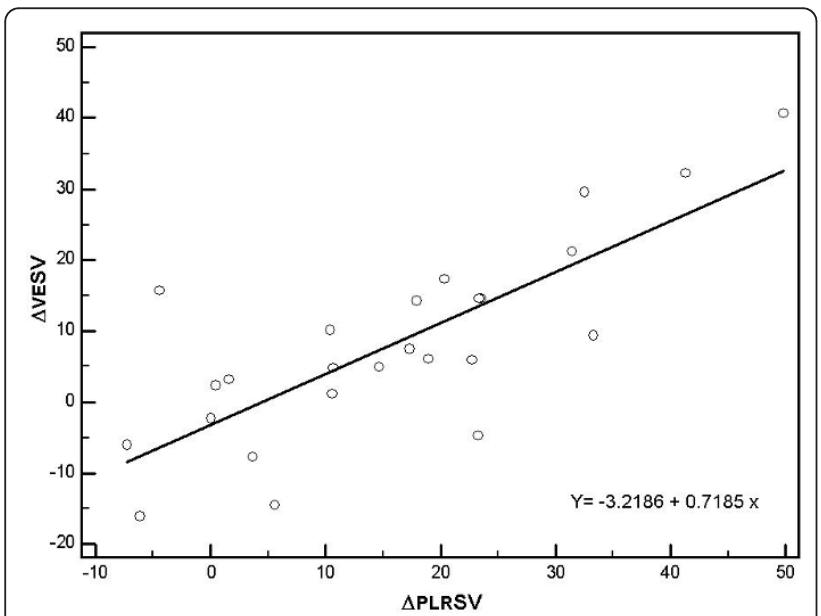

Figure 1 Relation between changes in stroke volume induced by PLR ( $\triangle$ PLRSV) and changes in stroke volume induced by volume expansion $(\triangle \mathrm{VESV})$ patients, CVP increased by $\geq 2 \mathrm{mmHg}$ (six responders and four nonresponders). Among these patients, the AUCs were $0.83 \pm 0.13$ for $\triangle \mathrm{PLRSV}\left(\mathrm{CI}_{95}: 0.48\right.$ to 0.98 ; $P=0.012)$ and $0.83 \pm 0.13$ for $\triangle \mathrm{PLRCO}\left(\mathrm{CI}_{95}: 0.48\right.$ to

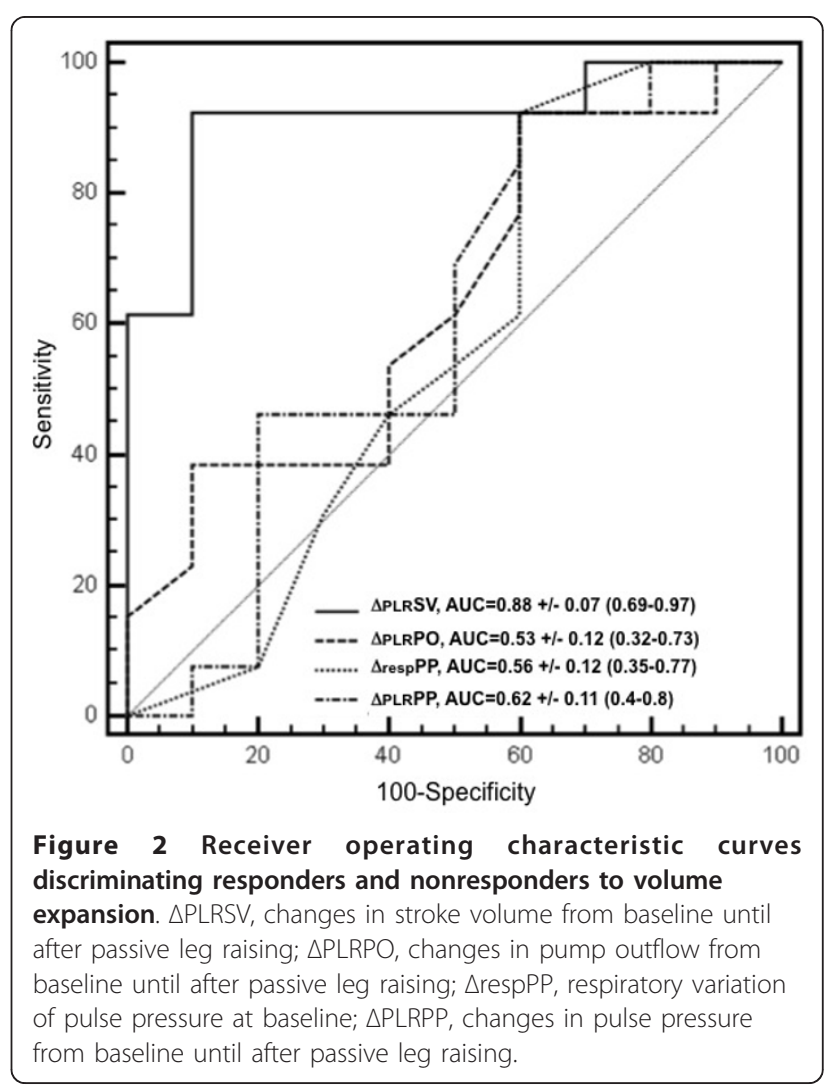


0.98; $P=0.012$ ). Table 4 reports the different threshold values of $\triangle$ PLRSV and $\triangle$ PLRCO.

\section{Discussion}

Our study demonstrates that a $10 \%$ increase $\triangle$ PLRSV predicts a $>15 \%$ increase in SV after VE in ARDS patients placed on venovenous ECMO (Figure 3). ECMO is an efficient treatment for refractory ARDS [22]. No studies have assessed the usual dynamic parameters of preload reserve on ECMO-assisted patients, probably because of the complex interactions between the protective mechanical ventilation and ECMO system on heartlung interaction. As previously shown in the context of ARDS without ECMO support, neither $\triangle$ respPP nor $\triangle$ PLRPP predicts fluid responsiveness [8-10,12]. In two prospective studies, the poor predictive performance of $\Delta$ respPP has been attributed to insufficient changes in transpulmonary and pleural pressure $[10,12]$, which are related to protective ventilation and altered pulmonary compliance. In addition, $\Delta$ respPP could reflect postload variation on right ventricular dysfunction and cannot be used as a predictor even in the presence of hypovolaemia $[8,9,11]$. Such clinical situations are frequent in the treatment of ECMO-assisted patients, which limit the use of such indices. ECMO patients with late ARDS were ventilated with 'ultraprotective' ventilation because of altered compliance and a high incidence of acute cor pulmonale (Table 1). As $\Delta$ resp indices must be avoided because they fail to predict fluid responsiveness and fluid overload, fluid management may rely on a reversible and safe fluid challenge. Thus, we assessed predictive values of $\triangle P L R$ indices.

$\triangle$ PLRPP cannot predict fluid responsiveness, even among patients with a minimal increase in CVP of 2 mmHg. On the basis of physiological knowledge, the use of PP as a substitute for SV would assume constant arterial compliance. By increasing intrathoracic blood volume, PLR may also induce sympathetic activation; however, our patients were deeply sedated, and their HRs remained unchanged during PLR. In clinical practice, SV, PP and vascular tone can vary with the patient's haemodynamic conditions and can be altered by PLR [28], which may have been the case in our present study.

In this context, echocardiographic measurement of $\triangle$ PLRSV and $\triangle \mathrm{PLRCO}$ may predict fluid responsiveness. The best threshold was $5 \%$ for $\triangle \mathrm{PLRSV}$, with $92 \%$ sensitivity $\left(\mathrm{CI}_{95}: 64\right.$ to 100$)$ and $83 \%$ specificity $\left(\mathrm{CI}_{95}: 52\right.$ to $98)$, and $5 \%$ for $\triangle \mathrm{PLRCO}$, with $85 \%$ sensitivity $\left(\mathrm{CI}_{95}: 46\right.$ to 95$)$ and $83 \%$ specificity $\left(\mathrm{CI}_{95}: 52\right.$ to 98 ) (Table 4 ). The lower sensitivity of $\triangle$ PLRCO may be explained by the fact that $\mathrm{CO}$ is the product of SV and HR. In some responders, the VE-induced SV increase was associated with decreased HR (nonsignificantly). Whereas sensitivity differed, the $\triangle \mathrm{PLRCO}$ and $\triangle \mathrm{PLRSV}$ AUCs were not statistically different. Taking into account echocardiography, interindividual reproducibility and the fact that we wanted to avoid volume overloading, a threshold of $10 \%$ for $\triangle$ PLRSV was proposed, with $92 \%$ specificity and $62 \%$ sensitivity (Table 4 and Figure 3 ).

Although ECMO modifies the right-sided heart load condition and interferes with pulmonary artery circulation $[20,23,24]$, it does not prevent an increase in venous return, as also reflected by increased CVP and persistent fluid responsiveness during PLR and after VE with sensitivity and specificity percentages comparable to values usually recorded in the ICU without ECMO [13-15,17]. One assumption might be that, in hypovolaemic patients, fluid expansion may load the ECMO pump first and alter VE (and $\triangle$ PLR predictive values), as patients' SV may not increase. In four nonresponders, PO increased but SV also increased by $>10 \%$. Moreover, $\triangle$ PLRSV were correlated with VE-induced SV variations, with values close to those recorded in the ICU among patients not being treated with ECMO [14]. Thus, in nonresponders, an increase in CVP without a change in $\mathrm{CO}$ and $\mathrm{PO}$ confirms an increase in right-sided preload and the fact that fluid expansion should not refill the ECMO system. Unlike Lakhal et al. [15], we found that the CVP measurement did not improve the

Table 4 Accuracy of stroke volume and cardiac output changes after passive leg raising to predict fluid responsiveness $^{\mathrm{a}}$

\begin{tabular}{|c|c|c|c|c|c|c|}
\hline Criteria & Sensitivity & Specificity & LR+ & LR- & PPV & NPV \\
\hline$\triangle P L R S V>3 \%$ & $92 \%(64$ to 100$)$ & $67 \%$ (35 to 90$)$ & 2.7 (1.8 to 4.3$)$ & $0.12(0.01$ to 0.9$)$ & $75 \%$ (48 to 93 ) & $89 \%(49$ to 100$)$ \\
\hline$\triangle P L R S V>5 \%$ & $92 \%(64$ to 100$)$ & $83 \%$ (52 to 98 ) & 5.5 (4.1 to 7.7$)$ & 0.09 (0.01 to 0.9) & $86 \%$ (57 to 98 ) & $91 \%$ (59 to 100$)$ \\
\hline$\triangle \mathrm{PLRSV}>10 \%$ & $62 \%$ (32 to 86$)$ & $92 \%$ (62 to 100$)$ & 7.3 (4.7 to 11.7 ) & $0.42(0.06$ to 3.1$)$ & $89 \%$ (52 to 100 ) & $69 \%$ (40 to 90 ) \\
\hline$\triangle P L R S V>15 \%$ & $39 \%$ (14 to 68$)$ & $92 \%(62$ to 100$)$ & 4.6 (2.3 to 9.4$)$ & 0.67 (0.1 to 4.6) & $83 \% 36$ to 100$)$ & $58 \%(34$ to 80$)$ \\
\hline$\triangle P L R C O>3 \%$ & $92 \%(64$ to 100$)$ & $67 \%$ (35 to 90 ) & 2.8 (1.8 to 4.3$)$ & $0.12(0.01$ to 0.9$)$ & $75 \%$ (48 to 93 ) & $89 \%$ (49 to 100$)$ \\
\hline$\triangle \mathrm{PLRCO}>5 \%$ & $85 \%$ (46 to 95 ) & $83 \%$ (52 to 98 ) & 5 (3.6 to 7.2 ) & $0.18(0.03$ to 1.1$)$ & $85 \%$ (55 to 98 ) & $83 \%$ (52 to 98 ) \\
\hline$\triangle P L R C O>8 \%$ & $69 \%$ (39 to 91 ) & $83 \%$ (52 to 98$)$ & 4.1 (2.7 to 6.5$)$ & 0.37 (0.08 to 1.7$)$ & $82 \%$ (48 to 98 ) & $71 \%$ (42 to 92 ) \\
\hline$\triangle P L R C O>12 \%$ & $54 \%(25$ to 81$)$ & $83 \%$ (52 to 98$)$ & $3.2(1.8$ to 5.7$)$ & 0.55 (0.1 to 2.2) & $78 \%$ (38 to 98 ) & $63 \%$ (35 to 85$)$ \\
\hline
\end{tabular}

aLR+, positive likelihood ratio; LR-, negative likelihood ratio; PPV; positive predictive value; NPV, negative predictive value; $\triangle$ PLRSV, stroke volume increase from baseline and after passive leg raising; $\triangle \mathrm{PLRCO}$, increase of cardiac output increase from baseline and after passive leg raising. Data are raw numbers and $\mathrm{Cl}_{95}$ ranges. 


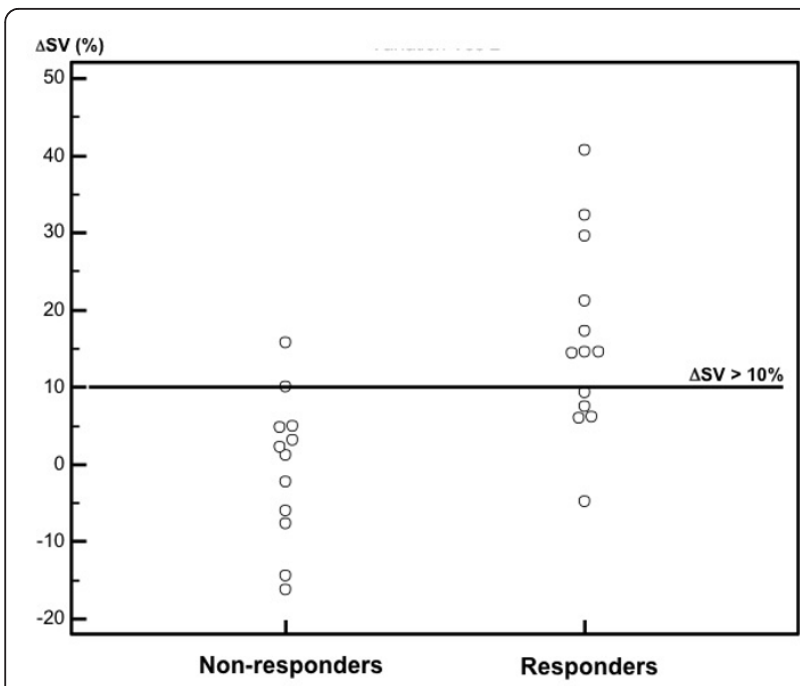

Figure 3 Passive leg raising (PLR)-induced stroke volume (SV) increase in responders and nonresponders. $\triangle S V$, stroke volume increase between baseline and PLR expressed as a percentage.

accuracy of $\triangle P L R$ indices. CVP values should be analysed with caution, even if the mean CVP values increased with PLR and VE. Since the distal extremities of the ECMO canula and $\mathrm{CVC}$ are close, the CVP mean value may vary depending on measurement variations. In addition, this subgroup analysis was performed in only 10 patients.

Since venous return and pump venous injection are preload- and afterload-dependent processes, we assumed that ECMO parameters could demonstrate preloaddependent conditions. At baseline, the PO/RPM ratio, which may reflect $\mathrm{PO}$ adequacy to preload status, was not different between the two groups. PLR and VE increase $\mathrm{PO}$ and PO/RPM ratio and decreased PI only when the patient was preload-dependent, that is, only in responders (Table 3). Nevertheless, $\triangle$ PLRPO was not predictive of fluid responsiveness (Figure 2). Different mechanisms may explain this result. First, low variations in PO may have exposed $\triangle \mathrm{PLRPO}$ to an insufficient signal-to-noise ratio that was distorted by our method of calculating PO. Second, the afterload dependency of ECMO may alter PO. As we did not investigate ECMO afterload, we cannot link an increase in $\mathrm{PO}$ to an increase in ECMO preload and/or a decrease in ECMO afterload. Indeed, the present results confirm the cardiac dependence of the venovenous ECMO circuit. The venovenous ECMO circuit acts as a cardiac preload sensor (more than a volume sensor). Nonetheless, for the reasons mentioned above, we have not demonstrated that $\triangle \mathrm{PLRPO}$ is predictive of fluid responsiveness.

This study has a number of limitations. The small number of measurements may limit the interpretation of the results, but this number is comparable to the sample sizes of other published studies and the statistical significance is sufficient [17]. The $\triangle \mathrm{PLRSV}$ cutoff is close to ultrasonic interindividual reproducibility. This threshold is comparable to values usually recorded in the ICU $[17,29]$ and is more than twice the values of inter-and intraindividual reproducibility. We assessed SV using TTE, which has been validated against the thermodilution technique [30]. Thermodilution monitoring cannot be used because of recirculation phenomena [31], and preload reserve haemodynamic indices are not currently validated in this setting for the reasons described above. There were some concerns about the safety of PLR among ECMO patients. In our cohort, all patients underwent PLR without any adverse impact on the ECMO system. Before PLR, however, precautions were taken regarding the length of inflow and outflow cannulas.

\section{Conclusions}

In this study, a $>10 \%$ increase in $\triangle$ PLRSV was predictive of fluid responsiveness in patients placed on venovenous ECMO respiratory assistance. This diagnostic procedure is easy to perform, reversible, familiar to intensive care physicians and easily reproducible, and it may be helpful in reliably identifying patients who will benefit from fluid loading. In contrast, we have not demonstrated that $\triangle \mathrm{PLRPO}$ and $\triangle \mathrm{respPP}$ can be used to predict volume responsiveness. Further studies of a larger sample of patients placed on various types of ECMO are necessary to assess these results.

\section{Key messages}

- Derivative pulse pressure indices $(\Delta$ respPP and $\triangle$ PLRPP) failed to predict fluid responsiveness in ARDS patients placed on venovenous ECMO.

- A > 10\% increase of $\triangle$ PLRSV may predict fluid responsiveness in patients treated with venovenous ECMO.

- $\triangle$ PLRPO cannot be used to predict fluid responsiveness.

\section{Abbreviations}

$\triangle P L R P O$ : passive leg raising pump outflow change; $\triangle P L R P P$ : passive leg raising pulse pressure change; $\triangle P L R S V$ : passive leg raising stroke volume change; $\triangle$ respPP: respiratory pulse pressure variation; $\triangle$ respSV: respiratory stroke volume variation; ARDS: acute respiratory distress syndrome; $\mathrm{Cl}_{95}$ : 95\% confidence interval; CO: cardiac output; CVC: central venous catheter; CVP: central venous pressure; DAP: diastolic arterial pressure; ECMO: extracorporeal membrane oxygenation; IRB: Institutional Review Board; LVEF: left ventricular ejection fraction; MAP: median arterial pressure; PI: pulse index; PO: pump outflow; PLR: passive leg raising; ROC: receiver operating characteristic; RPM: rotation per minute; SAP: systolic arterial pressure; SD: standard deviation; SV: stroke volume; TTE: transthoracic echocardiography; VE: volume expansion; VTIAo: aortic velocity-time integral ratio.

\section{Acknowledgements}

We thank Marie-Claude Guérin for reviewing the manuscript. We received no financial support for conducting this study. This study was approved by the Institutional Review Board of Amiens University Hospital. 


\section{Author details}

'Department of Anesthesiology and Critical Care, Amiens University Hospital, Place Victor Pauchet, Amiens, F-80054, France. ${ }^{2}$ Department of Cardiac Surgery, Amiens University Hospital, Place Victor Pauchet, Amiens, F-80054, France. ${ }^{3}$ INSERM, ERI12, Jules Verne University of Picardy, 12 rue des Louvels, Amiens, F-80000, France.

\section{Authors' contributions}

PGG conceived, designed and coordinated the study and drafted the manuscript. EZ, MD and TC participated in the coordination of the study. $M M, V H, L B$ and EB participated in the coordination of the study and helped in drafting the manuscript. HD performed the statistical analysis and helped in drafting the manuscript.

\section{Competing interests}

The authors declare that they have no competing interests.

Received: 26 April 2011 Revised: 2 August 2011

Accepted: 18 September 2011 Published: 18 September 2011

\section{References}

1. Michard F, Teboul JL: Predicting fluid responsiveness in ICU patients: a critical analysis of the evidence. Chest 2002, 121:2000-2008.

2. Michard F, Boussat S, Chemla D, Anguel N, Mercat A, Lecarpentier Y, Richard C, Pinsky MR, Teboul JL: Relation between respiratory changes in arterial pulse pressure and fluid responsiveness in septic patients with acute circulatory failure. Am J Respir Crit Care Med. 2000, 162:134-138.

3. Reuter DA, Felbinger TW, Schmidt C, Kilger E, Goedje O, Lamm P, Goetz AE: Stroke volume variations for assessment of cardiac responsiveness to volume loading in mechanically ventilated patients after cardiac surgery. Intensive Care Med 2002, 28:392-398.

4. Feissel M, Michard F, Mangin I, Ruyer O, Faller JP, Teboul JL: Respiratory changes in aortic blood velocity as an indicator of fluid responsiveness in ventilated patients with septic shock. Chest 2001, 119:867-873.

5. Michard F, Teboul JL: Using heart-lung interactions to assess fluid responsiveness during mechanical ventilation. Crit Care 2000, 4:282-289.

6. National Heart, Blood Institute Acute Respiratory Stress Syndrome (ARDS) Clinical Trials Network, Wiedemann HP, Wheeler AP, Bernard GR, Thompson BT, Hayden D, deBoisblanc B, Connors AF Jr, Hite RD, Harabin AL: Comparison of two fluid-management strategies in acute lung injury. N Engl J Med 2006, 354:2564-2575.

7. Jia X, Malhotra A, Saeed M, Mark RG, Talmor D: Risk factors for ARDS in patients receiving mechanical ventilation for $>48 \mathrm{~h}$. Chest 2008, 133:853-861.

8. Mahjoub Y, Pila C, Friggeri A, Zogheib E, Lobjoie E, Tinturier F, Galy C, Slama M, Dupont H: Assessing fluid responsiveness in critically ill patients: false-positive pulse pressure variation is detected by Doppler echocardiographic evaluation of the right ventricle. Crit Care Med 2009, 37:2570-2575.

9. Daudel F, Tüller D, Krähenbühl S, Jakob SM, Takala J: Pulse pressure variation and volume responsiveness during acutely increased pulmonary artery pressure: an experimental study. Crit Care 2010, 14: R122.

10. De Backer D, Heenen S, Piagnerelli M, Koch M, Vincent JL: Pulse pressure variations to predict fluid responsiveness: influence of tidal volume. Intensive Care Med 2005, 31:517-523.

11. Daudel F, Tüller D, Krähenbühl S, Jakob SM, Takala J: Pulse pressure variation and volume responsiveness during acutely increased pulmonary artery pressure: an experimental study. Crit Care 2010, 14: R122.

12. Lakhal K, Ehrmann S, Benzekri-Lefèvre D, Runge I, Legras A, Dequin PF, Mercier E, Wolff M, Régnier B, Boulain T: Respiratory pulse pressure variation fails to predict fluid responsiveness in acute respiratory distress syndrome. Crit Care 2011, 15:R85.

13. Monnet X, Rienzo M, Osman D, Anguel N, Richard C, Pinsky MR, Teboul JL: Passive leg raising predicts fluid responsiveness in the critically ill. Crit Care Med 2006, 34:1402-1407.

14. Préau S, Saulnier F, Dewavrin F, Durocher A, Chagnon JL: Passive leg raising is predictive of fluid responsiveness in spontaneously breathing patients with severe sepsis or acute pancreatitis. Crit Care Med 2010, 38:819-825.
15. Lakhal K, Ehrmann S, Runge I, Benzekri-Lefèvre D, Legras A, Dequin PF Mercier E, Wolff M, Régnier B, Boulain T: Central venous pressure measurements improve the accuracy of leg raising-induced change in pulse pressure to predict fluid responsiveness. Intensive Care Med 2010, 36:940-948.

16. Jabot J, Teboul JL, Richard C, Monnet X: Passive leg raising for predicting fluid responsiveness: importance of the postural change. Intensive Care Med 2009, 35:85-90.

17. Cavallaro F, Sandroni C, Marano C, La Torre G, Mannocci A, De Waure C, Bello G, Maviglia R, Antonelli M: Diagnostic accuracy of passive leg raising for prediction of fluid responsiveness in adults: systematic review and meta-analysis of clinical studies. Intensive Care Med 2010, 36:1475-1483.

18. Esan A, Hess DR, Raoof S, George L, Sessler CN: Severe hypoxemic respiratory failure: Part 1. Ventilatory strategies. Chest 2010, 137:1203-1216

19. Raoof S, Goulet K, Esan A, Hess DR, Sessler CN: Severe hypoxemic respiratory failure: Part 2. Nonventilatory strategies. Chest 2010, 137:1437-1448.

20. Marasco SF, Lukas G, McDonald M, McMillan J, Ihle B: Review of ECMO (extra corporeal membrane oxygenation) support in critically ill adult patients. Heart Lung Circ 2008, 17(Suppl 4):S41-S47.

21. Iglesias $M$, Martinez E, Badia JR, Macchiarini P: Extrapulmonary ventilation for unresponsive severe acute respiratory distress syndrome after pulmonary resection. Ann Thorac Surg 2008, 85:237-244.

22. Davies A, Jones D, Bailey M, Beca J, Bellomo R, Blackwell N, Forrest $P$, Gattas D, Granger E, Herkes R, Jackson A, McGuinness S, Nair P, Pellegrino V, Pettilä V, Plunkett B, Pye R, Torzillo P, Webb S, Wilson M, Ziegenfuss M: Extracorporeal membrane oxygenation for 2009 influenza A(H1N1) acute respiratory distress syndrome. JAMA 2009, 302:1888-1895.

23. Larsson M, Talving P, Palmér K, Frenckner B, Riddez L, Broomé M: Experimental extracorporeal membrane oxygenation reduces central venous pressure: an adjunct to control of venous hemorrhage. Perfusion 2010, 25:217-223.

24. Germann P, Balassa A, Roeder G, Kaider A, Schlag G, Zimpfer M, Sladen R: Effects of inhaled nitric oxide and extracorporeal membrane oxygenation on pulmonary hemodynamics and lymph flow in oleic acid lung injury in sheep. Crit Care Med 1997, 25:1881-1887.

25. Sidebotham D, McGeorge A, McGuinness S, Edwards M, Willcox T, Beca J: Extracorporeal membrane oxygenation for treating severe cardiac and respiratory failure in adults: Part 2. Technical considerations. J Cardiothorac Vasc Anesth 2010, 24:164-172.

26. Grimes DA, Schulz KF: Refining clinical diagnosis with likelihood ratios. Lancet 2005, 365:1500-1505.

27. Vieillard-Baron A: Assessment of right ventricular function. Curr Opin Crit Care 2009, 15:254-260

28. Monnet X, Osman D, Ridel C, Lamia B, Richard C, Teboul JL: Predicting volume responsiveness by using the end-expiratory occlusion in mechanically ventilated intensive care unit patients. Crit Care Med 2009, 37:951-956.

29. Lamia B, Ochagavia A, Monnet X, Chemla D, Richard C, Teboul JL: Echocardiographic prediction of volume responsiveness in critically ill patients with spontaneously breathing activity. Intensive Care Med 2007, 33:1125-1132.

30. Huntsman LL, Stewart DK, Barnes SR, Franklin SB, Colocousis JS, Hessel EA Noninvasive Doppler determination of cardiac output in man: clinical validation. Circulation 1983, 67:593-602

31. Haller M, Zöllner C, Manert W, Briegel J, Kilger E, Polasek J, Hummel T, Forst $H$, Peter $K$ : Thermodilution cardiac output may be incorrect in patients on venovenous extracorporeal lung assist. Am J Respir Crit Care Med 1995, 152:1812-1817.

doi:10.1186/cc10451

Cite this article as: Guinot et al:: Passive leg raising can predict fluid responsiveness in patients placed on venovenous extracorporeal membrane oxygenation. Critical Care 2011 15:R216. 